NBER WORKING PAPER SERIES

\title{
HEDGING OPTIONS IN A \\ GARCH ENVIRONMENT: TESTING \\ THE TERM STRUCTURE OF \\ STOCHASTIC VOLATILITY MODELS
}

Robert F. Engle

Joshua Rosenberg

Working Paper No. 4958

\section{NATIONAL BUREAU OF ECONOMIC RESEARCH 1050 Massachusetts Avenue \\ Cambridge, MA 02138 \\ December 1994}

This paper is part of NBER's research program in Asset Pricing. Any opinions expressed are those of the authors and not those of the National Bureau of Economic Research.

() 1994 by Robert F. Engle and Joshua Rosenberg. All rights reserved. Short sections of text, not to exceed two paragraphs, may be quoted without explicit permission provided that full credit, including $\odot$ notice, is given to the source. 


\title{
HEDGING OPTIONS IN A \\ GARCH ENVIRONMENT: TESTING \\ THE TERM STRUCTURE OF \\ STOCHASTIC VOLATILITY MODELS
}

\begin{abstract}
This paper develops a methodology for testing the term structure of volatility forecasts derived from stochastic volatility models, and implements it to analyze models of S\&P 500 index volatility. Volatility models are compared by their ability to hedge options positions sensitive to the term structure of volatility. Overall, the most effective hedge is a Black-Scholes (BS) delta-gamma hedge, while the BS delta-vega hedge is the least effective. The most successful volatility hedge is GARCH components delta-gamma, suggesting that the GARCH components estimate of the term structure of volatility is most accurate. The success of the BS delta-gamma hedge may be due to mispricing in the options market over the sample period.
\end{abstract}

Robert F. Engle

Department of Economics, 0508

University of California, San Diego

9500 Gilman Drive

La Jolla, CA 92093-0508

and NBER
Joshua Rosenberg

Department of Economics, 0508

University of California, San Diego 9500 Gilman Drive

La Jolla, CA 92093-0508 


\section{Introduction}

Estimating the term structure of volatility has, in the past, focused on option implied volatility. For instance, Stein (1989) estimated the term structure of volatility using an autoregressive volatility model derived from implied volatilities. He found the actual sensitivity of medium term to short term implieds was greater than the estimated sensitivity from the forecast term structure, and concluded that medium term implied volatilities overreact to information. Diz and Finucane (1993) rejected the overreaction hypothesis using different estimation techniques. They found some evidence for underreaction of medium term implieds.

Heynen et. al. (1994) estimated the term structure of volatility by comparing how well elasticity parameters generated by autoregressive volatility (ARV), GARCH, and EGARCH models explained the relationship between long term and short term implied variances for Philips and the EOE index. The EGARCH model was found to best model this relationship, and, thus to represent the best estimate of the term structure of volatility. $\mathrm{Xu}$ and Taylor (1994) used regression and Kalman filter techniques to fit a term structure model to the time series of forward implied variances for currency options.

Since we cannot observe actual market volatility, tests of the performance of the term structure implied by different volatility models necessarily take an indirect form. The previous papers use the implied volatility of different maturity options as point estimates of the term structure of average volatility. This paper takes a different approach, using hedging tests as the basis for comparing volatility models. Because option price changes are an observable feature, and their 
behavior is partly determined by changes in underlying asset's volatility, it is natural to relate hedging effectiveness to the accuracy of the volatility models.

In our tests, a medium term option position (call, put or straddle) is held and hedged with other assets. First, an appropriate amount of the most similar short term position is sold to hedge the volatility sensitivity of the medium term position. Then, an appropriate amount (delta) of the underlying stock is purchased or sold to eliminate first order price risk. Of course, the key to a successful hedging program is determination of these 'appropriate' amounts, which correspond to the hedging ratios derived from different assumptions about the volatility process.

Hedging volatility in a pure Black-Scholes world is not necessary, since volatility is assumed to be constant over the life of the option. However, a natural generalization of BS is to consider the effect of a unit change in volatility on the option price. To eliminate the volatility sensitivity of an option position, a vega hedge is formed by selling a second option.

An alternative hedge that can be constructed with a second option is a gamma hedge, which eliminates risk associated with non-linearity of the option price response to changes in the underlying price. This non-linearity is also known as convexity and optionality. Analogous hedges can be constructed under various models of stochastic volatility.

Clearly, the optimal number of short term options to short per medium term option, the vega hedge ratio, depends on sensitivity of the options prices to volatilities and on the estimated term structure of volatility. If movements in a state variable affect primarily short volatilities rather than long volatilities, then 
it will take relatively few short options to hedge this risk. Thus, the accuracy of the forecast term structure of volatility is a key determinant of vega hedging performance.

We also test efficiency in the options market by searching for trading strategies that earn excess profits. The ability to earn excess profits is an indicator of inefficiency and thus mispricing. We are concerned with mispricing because hedging ratios depend on a correct pricing formula. Deviations from this formula will diminish hedging performance and may impair comparisons of volatility models. Our tests of inefficiency focus on time spreads and jelly rolls, which are positions whose prices are sensitive to the term structure of volatility. We also consider straddles, which are volatility sensitive portfolios.

This paper is structured as follows. Section II presents a general method for option pricing under stochastic volatility, and Section III presents a general method for hedging. Section IV applies these methods to several stochastic volatility models. In Section V, the stochastic volatility models are estimated and their hedging performance is tested. Section VI explores the effects of mispricing, and Section VII concludes the study.

\section{Pricing options in a stochastic volatility environment}

Pricing options in a stochastic volatility environment is not a solved problem, at least in practice. Theoretically, the value of a European style put option which eliminates arbitrage possibilities can be found from

(1) $P_{t}=E_{t}^{o}\left[\max \left(K-S_{T}, 0\right)\right]$ 
where the expectation is taken with respect to the risk-neutral distribution as of time $t$. In the equation, $K$ is the strike price, $S$ is the underlying price and $T$ is the expiration date. The risk-free rate of interest is taken to be zero for ease of notation. This expression is only useful once the risk-free conditional distribution is specified, and this paper can be thought of as seeking useful parameterizations.

When the underlying asset follows a geometric Brownian motion with constant volatility, then it is well known that a solution to (1) is the Black-Scholes (1973) formula which can be written as

$$
P_{t}=B S\left(\sigma, S_{t}, T\right)
$$

In this case, $\sigma$ is the constant volatility which is also the average daily volatility over the life of the option. Hull and White (1987) point out that if volatility is stochastic and independent of the stock price path, then the expectation conditional on average volatility, can be taken conditionally in (1) to get

$$
P_{t}=E_{t}^{o}\left\{E_{\imath}^{o}\left[\max \left(K-S_{T}, 0\right)\right] \mid \sigma\right\}=E_{t}^{o}\left\{B S\left(\sigma, S_{t}, T\right)\right\}
$$

as long as $S_{t}$ is conditionally lognormal. For at-the-money options, the BlackScholes formula is approximately linear in volatility. Therefore, a striking simplification of Hull and White is the Black-Scholes Plug-in (BSP) given as

$$
P_{\imath}=B S P\left(E_{t}^{o}(\sigma), S_{t}, T\right)
$$

Various options pricing formulas result from various assumptions about the process of the volatility. In each case however, it is natural to suppose that the most recent stock price $S_{\mathfrak{l}}$, which is known, would have potential value in 
forecasting average volatility over the life of an option. Thus, the optimal forecast will be expressed as a function the stock price.

$$
P_{t}=\operatorname{BSP}\left(\hat{\sigma}\left(S_{t}\right), S_{t}, T\right)
$$

Hedging parameters are then derived by differentiating BSP with respect to the volatility model's random variables as well as the familiar variables in BS. An approach that does not rely on the plug-in formulation can be implemented directly from (1) using simulation methods and particular specifications of the risk-neutral distribution.

\section{Hedging options in a stochastic volatility environment}

In order to hedge option portfolios that are held for discrete periods of time, where this period is long enough that volatility news is observed, but short enough so that a dynamic hedge is impractical, it is useful to develop a discrete time hedging formula. A one day holding period is used for this application. When a day passes, the option value will change in part because the underlying asset price changes and in part because the volatility changes. Changes due solely to the passage of time or changes in interest rates will be ignored.

To approximate the change in the option value, a Taylor series expansion is typically used. In this case, it is natural to think of expanding the option price at tomorrow's close as a function of tomorrow's state variables. Evaluating the derivatives of (2) at today's values of the state variables, gives the familiar BlackScholes delta, gamma, and vega hedge parameters for constant volatility: 


\section{Engle and Rosenberg}

$$
\begin{aligned}
& \Delta_{B S}=\frac{\partial P_{t+1}}{\partial S_{t+1} S_{t+1}=S_{t}} \\
& \Gamma_{B S}=\frac{\partial^{2} P_{t+1}}{\partial S_{t+1}^{2} S_{t+1}=S_{t}} \\
& \Lambda_{B S}=\frac{\partial P_{t+1}}{\partial \sigma}
\end{aligned}
$$

In a stochastic volatility environment, the chain rule can be used to develop extended hedge parameters. These will depend upon the form of the stochastic volatility process and will be combinations of the BS delta, gamma, vega, and derivatives of the volatility process. For example, the stochastic volatility (SV) delta is given by

$$
\Delta_{S V}=\Delta_{B S}+\Lambda_{B S} \frac{1}{2 \hat{\sigma}} \frac{\partial \hat{\sigma}^{2}}{\partial S_{t+1} S_{t+1}=S_{t}}
$$

For all the volatility processes used here, the first derivative of variance with respect to price is zero, since both positive and negative price movements increase volatility equally. However, models such as the EGARCH (Nelson, 1991) and AGARCH will have non-zero first derivatives and will therefore affect the deltas.

More interestingly, the gammas are potentially very different in a stochastic volatility environment in which volatility depends on the underlying stock price.

$$
\Gamma_{S V}=\Gamma_{B S}+\Lambda_{B S} \frac{1}{2 \hat{\sigma}} \frac{\partial^{2} \hat{\sigma}^{2}}{\partial S^{2}{ }_{t+1} S_{t+1}=S_{t}}
$$

The stochastic volatility gamma effectively incorporates both a volatility hedge and a hedge against non-linear price response, since it includes both BS vega and BS gamma. 
For volatility processes in which the relationship between price and volatility shocks is ignored, such as the BS and ARV models, the stochastic volatility gamma will have the same form as the BS gamma. The appropriate volatility hedge parameter is BS vega multiplied by the derivative of volatility with respect to the shock specific to the volatility process. The multiplier relates the change in volatility today to the change in average volatility.

For the BS model, vega is derived by considering a permanent change in the level of volatility which is deterministic, so the effect on the average volatility is the same as the effect on the contemporaneous volatility. Thus, the multiplier is one. For the ARV model, the shock considered directly effects the one day volatility forecast and has a declining effect on subsequent forecasts. So, the effect on average expected volatility is less than the effect on contemporaneous volatility, and the multiplier is less than one.

Hedging an option position entails reducing exposure to various risk factors, which correspond to random variables. In general, the most important risk factors are considered to be risk due to underlying price shocks, i.e. delta and gamma risk, and risk due to a volatility shock, i.e. vega risk. Exposure to the risk factors is measured using the hedging parameters, so that a hedge portfolio has zero exposure to some or all of these factors.

To create a delta-neutral hedge portfolio, it is necessary to short $\Delta$ of the underlying asset, where $\Delta$ is the delta hedge ratio. Since a put has a negative delta, the hedge involves a long position in the underlying asset. A straddle will typically have a delta close to zero already; and therefore, only small amounts of the underlying asset will be added to the portfolio. 
To create a vega-neutral or gamma-neutral hedge portfolio, a second option contract is required, since the underlying asset has a vega and gamma of zero. For the vega hedge, the hedge portfolio is short $\Lambda_{1} / \Lambda_{2}$ contracts of the second option, while the gamma hedge portfolio is short $\Gamma_{1} / \Gamma_{2}$. contracts of the second option. In each case, the hedge ratio is the number of contracts of the second option which are sold to hedge the first.

To compare the effectiveness of various hedging strategies, and thus the accuracy of the underlying volatility models, a series of hedged portfolios will be constructed based upon a particular theory of how volatility hedging should be accomplished. Each position will be held for one day. The returns on this series of portfolios will then be examined for effectiveness in hedging risks. The simplest measure of success is simply the volatility of the hedge portfolio.

In addition, the hedge portfolio returns will be regressed on the underlying return and return squared to see whether these risk factors are effectively eliminated. Finally the portfolio returns will be checked for serial correlation and $\mathrm{ARCH}$. Any finding of serial correlation suggests a mispricing of the assets, but there is no reason to suspect these portfolios would have constant variances, so the ARCH test is merely descriptive.

\section{Stochastic volatility models}

Four models of the term structure of volatility are examined in this paper: the autoregressive volatility model (ARV) which infers the term structure from implied volatilities, the GARCH(1,1) model, GARCH components model, and the Black-Scholes model which assumes that the term structure of volatility is 
deterministic and flat. These models differ in structure and in the type of shocks they allow to drive the volatility process. The differences between the models result in different hedge ratios, and provide a basis for comparisons using hedging tests. Details about each of the models are in Appendix A.

First, we will consider the ARV model. This is an approximation of what sophisticated traders use on Wall Street and has been described by Stein (1989) and Heynen, Kemna, and Vorst (1994). Let $\sigma_{1 \mathrm{t}}$ be the implied volatility of the first option contract on day $t$ and $\sigma_{2 t}$ the implied volatility of the second contract which is being used for hedging. These can be related by a regression:

$$
\sigma_{1}^{2}=\lambda \sigma_{2 t}^{2}+\mu+\eta_{t}
$$

in which $\lambda$ is estimated by least squares and is interpreted as the partial derivative of the first variance with respect to the second variance. In Stein (1989), the first contract is a medium term option, the second is a short term option, and $\lambda$ is the elasticity of medium term average volatility with respect to short term average volatility. Because of the substantial serial correlation in $\eta$, this can perhaps be better estimated in differenced form:

$$
\Delta \sigma_{1 t}^{2}=\lambda \Delta \sigma_{2 t}^{2}+\eta^{\prime}
$$

This $\lambda$ can be then used to construct optimal vega hedge ratios for options under ARV. In this case, the optimal number of short term options to sell for each medium term option held is $\lambda\left(\Lambda_{1} / \Lambda_{2}\right)\left(\sigma_{2} / \sigma_{1}\right)$. The inclusion of $\lambda$ is due to the fact that medium term volatility moves by $\lambda$ for a unit change in short term average volatility. The ratio of the standard deviations is due to the fact that the volatility 
process is parameterized in variance, while the state variable in BSP is in standard deviations.

Since lambda refers only to one pair of maturities, it is not generally applicable. Because each of these volatilities, $\sigma_{t}^{2}$, is the average of the volatilities for the remaining life of an option, it is natural to reparameterize the model in terms of the one day volatility parameter to arrive at the more familiar specification for an ARV model.

$$
\sigma_{t}^{2}=\rho\left(\sigma_{t-1}^{2}-\omega\right)+\omega+\varepsilon_{t}
$$

where $\omega$ is the long run constant variance, so that

$$
\sigma_{u}^{2}=\omega+\frac{\left(1-\rho^{T_{1}}\right)}{(1-\rho)} \frac{1}{T_{1}}\left(\sigma_{t}^{2}-\omega\right)
$$

and the lambda for contracts with maturity $T_{1}$ and $T_{2}$ is:

$$
\lambda_{12 t}=\frac{T_{2}}{T_{1}}\left\lfloor\frac{\left(1-\rho^{T_{1}}\right)}{\left(1-\rho^{T_{2}}\right)}\right\rfloor
$$

This allows time variation in the hedge ratio due to the maturities of the contracts. Estimating $\rho$ requires backing it out from (13), where a particular $\lambda$ is estimated from the data on implieds. Now, ARV vegas can be computed by multiplying BS vega evaluated implied volatility by the derivative of implied volatility with respect to a volatility shock at time t. Notice that there is no historical data on the underlying asset used in this procedure. 
In this case, the term structure of volatility forecasts is upward or downward sloping depending on the level of today's volatility compared to the long term average. And, the steepness of the term structure is determined by the mean reversion parameter $\rho$.

In contrast to the ARV model, the GARCH(1,1) model (Bollerslev, 1986) uses historical data from the underlying asset to estimate the process of volatility. The GARCH model can be expressed as

$$
\sigma_{t}^{2}=\omega+\alpha\left(\varepsilon_{t-1}^{2}-\omega\right)+\beta\left(\sigma_{t-1}^{2}-\omega\right)
$$

where $\varepsilon_{\mathrm{t}}=\left(\mathrm{S}_{\mathrm{t}} / \mathrm{S}_{\mathrm{t}-1}-1\right), \sigma^{2}$ is the one day volatility, and $\omega$ is the long run volatility. For this model, multistep forecasts are easily computed from the one step conditional variances. The average variance from $t$ until $T_{1}$ is given by

$$
\sigma_{1 t}^{2}=\omega+\frac{1}{T_{1}}\left[\frac{1-(\alpha+\beta)^{T_{1}}}{1-\alpha-\beta}\right]\left(\sigma_{t+1}^{2}-\omega\right)
$$

This model, like the ARV model, implies a monotonic upward or downwards sloping term structure which mean-reverts at a rate alpha plus beta.

The GARCH components model was proposed by Engle and Lee (1993) and allows more complex lag distributions. It models volatility as mean reverting to a long run component of volatility, but this long run component itself mean reverts to a constant level. The process for volatility can be written as:

$$
\begin{aligned}
& \sigma_{t}^{2}=q_{t}+\alpha\left(\varepsilon_{t-1}^{2}-q_{t}\right)+\beta\left(\sigma_{t-1}^{2}-q_{t}\right) \\
& q_{t}=\omega+\rho\left(q_{t-1}-\omega\right)+\phi\left(\varepsilon_{t-1}^{2}-\sigma_{t-1}^{2}\right)
\end{aligned}
$$


where $\mathrm{q}$ is the long run component which mean reverts to $\omega$ at rate $\rho$, while instantaneous volatility $\sigma$ mean reverts to $q$ at a rate $\alpha+\beta$. This term structure is not necessarily monotonic since the day ahead, trend, and long term forecast all influence the $n$-step ahead forecasts. The forecast of the average volatility from $t$ to $T_{1}$ is now given by:

$$
\sigma_{t t}^{2}=\omega+\frac{1}{T_{1}}\left\lfloor\frac{1-(\alpha+\beta)^{T_{1}}}{1-\alpha-\beta}\right\rfloor\left(\sigma_{t+1}^{2}-q_{t+1}\right)+\frac{1}{T_{1}}\left\lfloor\frac{1-\rho^{T_{1}}}{1-\rho}\right\rceil\left(q_{t+1}-\omega\right)
$$

GARCH gammas are computed by taking the derivatives of (15) and (17) and substituting into (8). Since these derivatives are taken with respect to $S_{t+1}$, these formulas are derived by first advancing time one day further, and then recognizing that there are only $\mathrm{T}_{1}-1$ days remaining in the contract.

To better understand the hedging ratios derived from these models, consider hedging the volatility sensitivity of medium term at-the-money call with 30 days to maturity with a short term at-the-money call with 10 days to maturity. Hedging volatility in a generalized Black-Scholes model requires a BS vega hedge. This hedge shorts 1.73 of the short term contracts for each medium term contract. A hedge ratio greater than one is counterintuitive but reflects the increase in vega with maturity. This corresponds to an experiment where volatility is changed once and for all, and therefore has a larger impact on longer-lived options. Figure 1 illustrates that the term structure of BS vega is upward sloping.

To hedge the non-linear response to a price change, the BS gamma hedge is used. The hedge ratio is .57 indicating just over half a short term contract be shorted for each medium term contract. This is intuitive since the second derivative of the current stock price has dramatically reduced impact over longer horizons. As 
shown in Figure 2, for at-the-money options, the term structure of BS gamma is downward sloping.

In the ARV model, the effect of price shocks on volatility is ignored, so the stochastic vega hedge is used. The vega multiplier incorporates mean reversion in volatility, which somewhat counteracts the rise in vega with maturity. For this example and the estimated ARV model, the vega hedge ratio is .99 requiring a one-for-one hedge strategy.

Using GARCH models, the volatility hedge is formed using stochastic gamma hedge ratios, since volatility changes respond to underlying price changes. In this example, the $\operatorname{GARCH}(1,1)$ gamma hedge ratio is .90 , while the $\operatorname{GARCH}$ components gamma hedge ratio is .78 . Since these hedge ratios are approximately linear combinations of the BS gamma and BS vega, they lie between these extremes. The shape of the term structure and the persistence of shocks determines how these are weighted. In general, if only short term variances are sensitive to volatility shocks, then the weights will give more emphasis to the BS gamma. If the process is IGARCH, then more weight will be given to $\mathrm{BS}$ vega.

\section{Hedging test results}

We compare the term structures of the four volatility models by constructing hedges for medium term option positions using short term positions and the underlying asset. Since accuracy of the hedging ratios depends on the forecast term structure of volatility, we expect that the most effective hedges will be generated by the best volatility model. 
This paper uses daily data for the nearest-to-the-money Standard and Poor's 500 Index put and call option with closest and next-closest maturities. The data was gathered by Chicago Board Options Exchange and covers the period October 1985 through February 1992. Only the 654 data points for which option prices are available for the medium and short term calls and puts are included in the analysis. Options that are further than five percent from the money are excluded. See Table 1 for details.

\section{Estimating the volatility models}

The first step in the testing procedure was estimation of the stochastic volatility models. See Table 2 for details. The ARV model was estimated using an OLS regression of differenced implied medium term variance on the differenced implied short term variance. The lambda from this regression, .54 ,implies a rho of .93 , assuming that the medium term option has 37 days to maturity and the short term option 13. Diz and Finucane use maximum likelihood estimation to arrive at similar results for S\&P100 implieds.

From the implieds, there is strong evidence for mean reversion in volatility. The change in medium term implied volatility is a fraction of the change in the short term implied. Also, short term implied variances and their first differences are more volatile than for medium term. That is, the volatility of volatility is declining with maturity. This is consistent with raw data for option prices, which indicates that short term option portfolios are substantially more volatile than medium term portfolios.

The GARCH $(1,1)$ and GARCH components models are estimated using maximum likelihood estimation. The $\operatorname{GARCH}(1,1)$ model assumes an underlying normal 
density, and the components model assumes that the underlying density is Student's-t. The GARCH decay parameter is .97 , which implies mean reversion in volatility and a declining volatility of volatility. The components model also exhibits this pattern.

The BS hedges use the one step ahead $\operatorname{GARCH}(1,1)$ forecast as the estimate of future volatility at all dates. Even if there are no volatility shocks, it is reasonable to update the volatility estimates daily using the most current information. The original BS model assumes that volatility is deterministic and constant over the life of the option. However, to investigate volatility hedges under BS, we consider the effect of a permanent change in the level of volatility.

Using these models, it is straightforward to estimate hedge ratios. Calculating average hedge ratios generated by the models over the sample period gives a clearer picture of the model differences. For near-the-money call positions, all average hedge ratios are less than one except for the BS and ARV vega hedges. This is due to the strong upward slope of the vega term structure. In addition, the slope of the term structure of hedge ratios flattens for all models except the BS and ARV. The BS gamma hedge and the GARCH components hedge have the lowest hedge parameters and are also closest to the empirical best hedge parameters. Details are in Table 3.

\section{Hedging tests}

The hedging tests are implemented as follows. Each trading day, three one hundred dollar portfolios are purchased. One contains medium term calls, one medium term puts, and one medium term 1:1 straddles. Then, hedge ratios are 
calculated and hedge portfolios created based on the appropriate formula from each stochastic volatility model.

For tests of the ARV and BS models, each portfolio is vega hedged by selling the appropriate number of short term positions. For tests of the $\operatorname{GARCH}(1,1)$, GARCH components model, and BS model, each portfolio is gamma hedged by selling the appropriate number of short term options. The short contract is designed to match the long contract, so that when long calls are being hedged, a short call is sold with the same strike. The same is true for puts and straddles. Finally, the entire portfolio is delta hedged with the composite delta. Each portfolio is held for one day and then sold. Price differences are calculated, and new positions established.

At the end of the analysis, the hedging effectiveness is calculated using the standard deviation of realized price changes for each hedge portfolio. Also, the best ex-post hedge portfolio is constructed by regressing the medium term calls, puts, and straddles on the underlying asset and the matching short term position. While the ex-post portfolio is unattainable in practice, it indicates reasonable average values for the hedge parameters, although there is no reason why it should not be dominated by a time-varying hedge ratio.

A number of conclusions can be drawn from the data. See Table 4 for details. Hedging with the underlying index, i.e. delta hedging, reduces the risk of the option positions by about $50 \%$ for the medium term calls and puts, but by a negligible amount for the straddle. This is expected since the straddle deltas are near zero. Hedging with a short term option position further reduces risk by about $4-12 \%$ using the best hedging ratios. The models performed best in hedging straddles, followed by puts, and then calls. 
Hedging performance can be ranked in terms of the average hedge ratio, with the models that generate the lowest hedge ratios doing best. The minimum risk hedges were generated by the BS delta-gamma hedge. It is important to note that this is not a volatility hedge; rather, it is a hedge against the non-linear option price response associated with large moves in the underlying price. If the BS model of volatility were correct, then a BS delta-vega hedge would also improve upon a delta hedge, by reducing the risk due to volatility shocks. In fact, the delta-vega hedges for both of the models in which volatility shocks ignore price information, the BS and ARV models, have significantly inferior performance compared to the delta hedge.

The second best hedging performance, and the best volatility hedging, was from the GARCH components delta-gamma hedge. It reduced risk over the delta hedge by $0 \%, 5 \%$, and $8 \%$ for calls, puts, and straddles. Its success may be due its flexible parameterization of the term structure of volatility. The $\operatorname{GARCH}(1,1)$ delta-gamma hedge did not improve on the delta hedge for calls, but reduced risk by $3 \%$ and $5 \%$ for puts and straddles. This provides evidence that GARCH models of volatility are useful in hedging the volatility sensitivity of options positions.

A perfectly hedged portfolio would have no structure in its price changes. None of the hedge portfolios are able to attain this goal. However, the price changes for hedge portfolios constructed using BS and GARCH components delta and gamma are uncorrelated with the index price change and square. No model consistently generates hedge price changes free of autocorrelation and heteroscedasticity.

\section{Interpretation of the results}


It is rather surprising that the best overall hedge is the BS delta-gamma hedge. This suggests that volatility should be treated as deterministic and constant over the life of the option, and that the relationship between price and volatility shocks can be safely ignored in hedging. In constrast, evidence from the BS delta-vega hedge indicates that if there are volatility shocks, they are not effectively hedged under the BS assumptions.

Is it possible that we have considered the wrong stochastic volatility models to generate hedging ratios? While this is probably true to some degree, it will not resolve this paradox. Any stochastic volatility process that depends on price changes will add some vega to the BS gamma and will generally give too large a hedge ratio over the sample period. Only if movements in short term volatility are systematically reversed after the short term option expires can the hedge ratio be reduced; this seems highly implausible as a continuing process.

Another potential explanation is that the Black-Scholes Plug-in approach to option pricing systematically overestimates hedge ratios. To examine this possibility, we revert to the basic option pricing model in equation (1) and simulate the riskneutral terminal distribution under several assumptions. In particular, this distribution is simulated under the $\operatorname{GARCH}(1,1)$ and GARCH component processes estimated in this paper. We use a numerical approach to estimate the GARCH gamma without using the Black-Scholes formula.

The finite difference method is used to estimate the GARCH gammas, using simulated option prices. Standardized shocks are drawn from a Student's-t distribution with 6 degrees of freedom to represent the leptokurtosis in the standardized residuals from the volatility models. These are generated for 40 
days with 10,000 replications, and option prices are calculated as the expected payoff from this risk-neutral distribution. The simulation is then restarted with the same random numbers and $S_{t+1}$ increased and decreased by $.5 \%$. The three option prices with the same strike and maturity are used to estimate gamma.

It appears that the problem with the hedge ratios is not a problem with the option pricing formulation, at least for these at-the-money options. The simulated GARCH gammas are very close to the BSP values and much higher than the BS gammas. Even the GARCH component model with leverage, which is simulated with the same persistence as the component model, has only a slightly lower hedge ratio. There is no clear definition of the BSP for this case, as the function is non-differentiable. See Table 3. We consider the possibility is that the options are mispriced in the next section.

\section{Option pricing tests}

Another explanation for the effectiveness of the BS delta-gamma hedge compared to stochastic volatility alternatives is mispricing in the S\&P500 index options market. A systematic overreaction of short maturity options to news would make them excessively variable and would make the low hedge ratio observed in our sample optimal. Mispricing may be in the market, or it may be due to data errors. In either case, the optimal hedge ratios may be different than those derived from BSP.

We test for mispricing by searching for trading strategies that earn excess profits, using a methodology similar to Noh, Engle, and Kane (1994) If the options market is not efficient in that it does not incorporate all available volatility information into current prices, then it may be possible to earn excess profits by 
using alternative volatility forecasts. The trading strategy we use is to compare stochastic volatility model option prices to market prices, buying options when model prices are below market prices and selling in the opposite situation. At the end of each day, a position is established, and it is sold at the end of the following day. If the market prices the next day move in the direction of the model prices, the model earns a profit. Otherwise, it has a loss.

To focus on the impact of mispricing on the hedging tests used in the previous section, we select option positions that are sensitive to the term structure of volatility. These positions are 1:1 call time spreads, 1:1 put time spreads, and a jelly roll. The time spreads consist of a medium term at-the-money option held long and a short term at-the-money option held short. The jelly roll consists of a 1:1 call time spread held long and a 1:1 put time spread held short. As a comparison to Noh et. al. (1994), we also test two volatility sensitive positions: short term at-the-money straddles and medium term at-the-money straddles.

The forecast volatilities used in the pricing tests are from the $\operatorname{GARCH}(1,1)$ model, the GARCH components model, and implicitly, the ARV model. The $\operatorname{GARCH}(1,1)$ model is used to generate forecasts of average volatility of the life of the option and the one-step ahead forecast The GARCH components model forecasts of average volatility of the life of the option are also used. The ARV model cannot be explicitly tested, since it implies that the prices derived from implied volatility are the correct prices. Of course, this will result in no trades, since model prices will be equal to market prices by definition. The ARV model is taken to imply a strategy of always buying one position. Of course, it is just as sensible to consider it as an always sell strategy, or probably even more reasonable is to use forecasts derived from an implied volatility regression as in Harvey and Whaley (1992). 
The first part of Table 5 shows the average profits and standard deviation of profits for each of the models. It is noteworthy that the 'Always buy' position earns trading profits that are not statistically different from zero at the .01 percent level for the term structure sensitive portfolios, but the trading profits are significantly negative for the volatility sensitive portfolios. This indicates that consistently selling straddles was a profitable strategy over the period, implying that the market volatility forecasts were too high on average, while the market term structure of volatilities was not biased in this way.

The GARCH forecasts earn excess profits for all the term structure sensitive positions, while the ARV model, which uses the market forecasts, earns zero profits. This indicates that there may be inefficiency in the market's processing of information to forecast the term structure of volatility. For the call time spreads, the models earn an average profit of about .16 points per position with a standard deviation of about 1 point. One point is equal to one hundred dollars. The profits are slightly higher and the volatility of price changes is lower for the put time spreads. The average prices of the call time spreads are about 4.3 points compared to 3.4 for the puts.

All of the models are predominantly option sellers as shown in the Summary of Trading Signals from Table 5. Each model, other than ARV, chooses to sell positions at least $80 \%$ of the time. This indicates that overall, the models find time spreads, jelly rolls, and straddles to be overpriced. In fact, all of the models, except the ARV model, are able to earn profits significantly greater than zero on sales of these positions. 
These tests reveal that a number of trading strategies based on alternative volatility forecasts are profitable over the sample period. Even a simple sell and hold strategy generates excess profits for straddles. This evidence is consistent with mispricing, which may explain why short term option prices are more variable than expected using the stochastic volatility models.

These findings are also consistent with previous studies. Noh et. al. (1994), which uses a portion of the same data set, finds substantial evidence that GARCH models can profitably forecast when to be short or long at-the-money straddles. Diz and Finucane (1993) find evidence for short-term overreaction of implieds, which indicates mispricing.

\section{Conclusions}

This paper provides a methodology for testing the term structure of volatility implied by stochastic volatility models, and implements it to analyze the term structure of S\&P500 index volatility. Hedging tests indicate that a BS deltagamma hedge is most effective, followed by a GARCH components delta-gamma hedge, which is the most effective volatility hedge. Volatility hedges that ignore the effects of price shocks on volatility, the ARV and BS delta-vega hedges, are ineffective. Mispricing in the option market during the sample period may explain the superiority of the BS delta-gamma hedge in our tests. 


\section{Engle and Rosenberg}

\section{APPENDIX A.}

Stochastic volatility model

$$
A R V: \quad \sigma_{t+1}^{2}-\bar{\sigma}^{2}=\rho\left[\sigma_{t}^{2}-\bar{\sigma}^{2}\right]+\varepsilon_{t}
$$

$\operatorname{GARCH}(1,1): \sigma_{t+1}^{2}=\omega(1-\alpha-\beta)+\alpha e_{t}^{2}+\beta \sigma_{t}^{2}$

GARCHcomp: $\sigma_{t+1}^{2}=q_{t+1}+\alpha\left(e_{t}^{2}-q_{t}\right)+\beta\left(\sigma_{t}^{2}-q_{t}\right)$

$$
q_{t+1}=\omega(1-\rho)+\rho q_{t}+\phi\left(e_{t}^{2}-\sigma_{t}^{2}\right)
$$

$\mathrm{n}$ - step ahead volatility

$$
\begin{aligned}
& A R V: \sigma_{t+k \mid t}^{2}=\bar{\sigma}^{2}+\rho^{k-1}\left[\sigma_{t}^{2}-\bar{\sigma}^{2}\right] \\
& \operatorname{GARCH}(1,1): \sigma_{t+k \mid t}^{2}=\omega+(\alpha+\beta)^{k-1}\left[\sigma_{t+1}^{2}-\omega\right] \\
& \text { GARCHcomp: } \sigma_{t+k \mid t}^{2}=\omega+(\alpha+\beta)^{k-1}\left(\sigma_{t+1}^{2}-q_{t+1}\right)+\rho^{k-1}\left(q_{t+1}-\omega\right)
\end{aligned}
$$

Average volatility over $T$ periods

$$
\begin{aligned}
& \text { for GARCH, } S_{t+1}=S_{t} \\
& A R V: \bar{\sigma}_{t+1}^{2}(T)=\bar{\sigma}^{2}+\frac{1}{T}\left\lceil\frac{1-\rho^{T}}{1-\rho}\right\rceil\left(\sigma_{t-1}^{2}-\bar{\sigma}^{2}\right)
\end{aligned}
$$

$\operatorname{GARCH}(1,1): \bar{\sigma}_{t+2}^{2}(T-1)=\omega+\frac{1}{T-1}\left[\frac{1-(\alpha+\beta)^{T-1}}{1-(\alpha+\beta)}\right]\left(\sigma_{t+2}^{2}-\omega\right)$

GARCHcomp: $\bar{\sigma}_{i+2}^{2}(T-1)=\omega+\frac{1}{T-1}\left\{\left[\frac{1-(\alpha+\beta)^{T-1}}{1-(\alpha+\beta)}\right\rceil\left(\sigma_{t+2}^{2}-q_{i+2}\right)+\left\lceil\frac{\left.1-\rho^{T}\right\rceil}{1-\rho}\right\rceil\left(q_{t+2}-\omega\right)\right\}$

Sensitivity of average standard deviation to a shock

$$
\begin{aligned}
& A R V: \frac{d \bar{\sigma}_{t+1}(T)}{d \varepsilon_{t}}=\frac{1}{2 \bar{\sigma}_{t+1}(T) T}\left\lfloor\frac{1-\rho^{T}}{1-\rho}\right\rfloor \\
& \text { GARCH: } \frac{d \bar{\sigma}_{t+2}(T-1)}{d S_{t+1}^{2}}=\frac{1}{2 \bar{\sigma}_{t+2}(T-1)}\left\lceil\frac{1-(\alpha+\beta)^{T-1}}{1-(\alpha+\beta)}\right] \frac{d^{2} \sigma_{t+2}^{2}}{d S_{t+1}^{2}} \\
& \text { GARCHcomp: } \frac{d \bar{\sigma}_{t+2}(T-1)}{d S_{t+1}^{2}}=\frac{1}{2 \bar{\sigma}_{t+2}(T-1)}\left\{\left[\frac{1-(\alpha+\beta)^{T-1}}{1-(\alpha+\beta)}\right] \frac{d^{2} \sigma_{t+2}^{2}}{d S_{t+1}^{2}}+\left[\frac{1-\rho^{T}}{1-\rho}\right] \frac{d^{2} q_{t+2}}{d S_{t+1}^{2}}\right\}
\end{aligned}
$$




\section{Engle and Rosenberg}

Elasticity of medium term average standard deviation with respect to short term average standard deviation

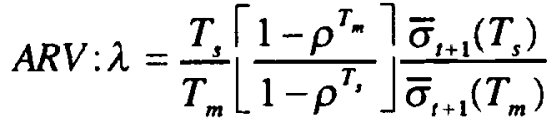

$$
\begin{aligned}
& \operatorname{GARCH}(1,1): \lambda=\frac{T_{s}-1}{T_{m}-1}\left[\frac{1-(\alpha+\beta)^{T_{m}-1}}{1-(\alpha+\beta)^{T_{s}-1}}\right] \frac{\bar{\sigma}_{t+2}\left(T_{s}-1\right)}{\bar{\sigma}_{t+2}\left(T_{m}-1\right)}
\end{aligned}
$$

GARCHcomp: $\lambda=\frac{T_{s}}{T_{m}} \frac{\bar{\sigma}_{t+2}\left(T_{s}-1\right)}{\bar{\sigma}_{t+2}\left(T_{m}-1\right)} \frac{\left\{\left[\frac{1-(\alpha+\beta)^{T_{m}-1}}{1-(\alpha+\beta)}\right] \frac{d^{2} \sigma_{t+1}^{2}}{d S_{t+1}^{2}}+\left[\frac{1-\rho^{T_{m}-1}}{1-\rho}\right] \frac{d^{2} q_{t+1}}{d S_{t+1}^{2}}\right\}}{\left\{\left[\frac{1-(\alpha+\beta)^{T-1}}{1-(\alpha+\beta)}\right] \frac{d^{2} \sigma_{t+1}^{2}}{d S_{t+1}^{2}}+\left[\frac{1-\rho^{T_{s}-1}}{1-\rho}\right] \frac{d^{2} q_{t+1}}{d S_{t+1}^{2}}\right\}}$

Hedge Ratios

$$
\begin{aligned}
& C V: G a m m a-\frac{\Gamma_{m}(\sigma)}{\Gamma_{s}(\sigma)} \\
& C V: V e g a:-\frac{\Lambda_{m}(\sigma)}{\Lambda_{s}(\sigma)} \\
& A R V:-\frac{\Lambda_{m}\left(\bar{\sigma}_{t+1}\left(T_{m}\right)\right) \frac{d \bar{\sigma}_{t+1}\left(T_{m}\right)}{d \varepsilon_{t}}}{\Lambda_{s}\left(\bar{\sigma}_{t+1}\left(T_{s}\right)\right) \frac{d \bar{\sigma}_{t+1}\left(T_{s}\right)}{d \varepsilon_{t}}} \\
& \operatorname{GARCH}(1,1):-\frac{\Gamma_{m}\left(\bar{\sigma}_{t+2}\left(T_{m}-1\right)\right)+\Lambda_{m}\left(\bar{\sigma}_{t+2}\left(T_{m}-1\right)\right) \frac{d^{2} \bar{\sigma}_{t+2}\left(T_{m}-1\right)}{d S_{t+1}^{2}}}{\Gamma_{s}\left(\bar{\sigma}_{t+2}\left(T_{s}-1\right)\right)+\Lambda_{s}\left(\bar{\sigma}_{t+2}\left(T_{s}-1\right)\right) \frac{d^{2} \bar{\sigma}_{t+2}\left(T_{s}-1\right)}{d S_{t+1}^{2}}}
\end{aligned}
$$

GARCHcomp: same as $\operatorname{GARCH}(1,1)$ but with different $2 \mathrm{~d}$ derivative 
Engle and Rosenberg

$-26-$

\section{Bibliography}

Black, F. and M. Scholes, 1973, "The Pricing of Options and Corporate Liabilities," Journal of Political Economy, 81, 637-654.

Bollerslev, T., 1986, "Generalized Autoregressive Conditional Heteroskedasticity," Journal of Econometrics, 31, 307-327.

Diz, F. and T. J. Finucane, 1993, "Do the Options Markets Really Overreact?," Journal Of Futures Markets, 13, 299-312.

Engle, R. F., 1982, “Autoregressive Conditional Heteroscedasticity with Estimates of the Variance of United Kingdom Inflation," Econometrica, 50, 987-1007.

Engle, R. F. and G. Lee, 1992, "A Permanent and Transitory Component Model of Stock Return Volatility," Discussion Paper, UC-San Diego 92-44.

Harvey, C. R. and R. E. Whaley, 1992, "Market Volatility Prediction and the Efficiency Of the S-and-P-100 Index Option Market," Journal Of Financial Economics, 31, 43-73.

Hull, J. and A. White, 1987, "The Pricing of Options on Assets with Stochastic Volatilities," Journal of Finance, XLII, 281-301.

Nelson, D. B., 1991, "Conditional Heteroskedasticity in Asset Returns: A New Approach," Econometrica, 59, 347-370.

Noh, J., R. F. Engle and A. Kane, 1994, "A Test of Efficiency for the S\&P500 Index Options Market Using Variance Forecasts," Journal of Derivatives, 2, 17-30.

Stein, J., 1989, "Overreactions in the Options Market," Journal Of Finance, 44, 1011-1023.

Xu, X. and S. J. Taylor, 1994, "The Term Structure of Volatility Implied by Foreign Exchange Options," Journal of Financial and Quantitative Analysis, 29, 57-74. 


\section{Table 1 - Summary of Options Data}

Data gathered by the Chicago Board Options Exchange, Daily, Oct. 1987-Feb. 1992

Nearest-to-the-money options for which current and next day's price are available are used in the study

\begin{tabular}{|c|c|c|c|c|c|c|c|}
\hline Year & 1986 & $1987^{*}$ & 1988 & 1989 & 1990 & 1991 & 1992 \\
\hline $\begin{array}{l}\text { Data Points } \\
\text { Available }\end{array}$ & 36 & 88 & 68 & 119 & 140 & 180 & 23 \\
\hline
\end{tabular}

\begin{tabular}{|c|c|c|c|c|c|c|c|c|c|c|}
\hline & $\begin{array}{l}\text { Medium Term } \\
\text { Call Options }\end{array}$ & $\begin{array}{l}\text { Short Term } \\
\text { Call Options }\end{array}$ & $\begin{array}{l}\text { Medium Term } \\
\text { Put Options }\end{array}$ & $\begin{array}{l}\text { Short Term } \\
\text { Put Options }\end{array}$ & $\begin{array}{l}\text { Modium Term } \\
\text { Put Options }\end{array}$ & $\begin{array}{l}\text { Medium Term } \\
\text { Straddles }\end{array}$ & $\begin{array}{l}\text { Short Term } \\
\text { Straddles }\end{array}$ & $\begin{array}{l}\text { Call 1:1 Time } \\
\text { Spreads }\end{array}$ & $\begin{array}{l}\text { Put 1:1 Time } \\
\text { Spreads }\end{array}$ & Jelly rolls \\
\hline Number & 654 & 654 & 654 & 654 & 654 & 654 & 654 & 654 & 654 & 654 \\
\hline Average Price & 9.874 & 5.546 & 8.083 & 4.720 & 8.083 & 17.957 & 10.266 & 4.329 & 3.363 & 0.966 \\
\hline Std. Price & 3.131 & 2.330 & 2.559 & 2.071 & 2.559 & 4.793 & 0.966 & 1.548 & 1.256 & 1.114 \\
\hline $\begin{array}{l}\text { Average Time } \\
\text { to Matur. }\end{array}$ & 37.2 & 13.5 & 37.2 & 13.5 & 37.2 & & & & & \\
\hline $\begin{array}{l}\text { Sid. Time to } \\
\text { Matur. }\end{array}$ & 13.7 & 6.5 & 13.7 & 6.5 & 13.7 & & & & & \\
\hline $\begin{array}{l}\text { Average } \\
\text { Moneyness }\end{array}$ & 1.002 & 1.002 & 1.002 & 1.002 & 1.002 & & & & & \\
\hline $\begin{array}{l}\text { Std. } \\
\text { Moneyness }\end{array}$ & 0.009 & 0.009 & 0.009 & 0.009 & 0.009 & & & & & \\
\hline
\end{tabular}




\section{Autoregressive Volatility Model (ARV)}

Regression of medium term differenced implied variance on short term Daily implied variance used is average of put and call implied variances 678 observations based on data availability from Oct. 1985-Feb. 1992

\begin{tabular}{|c|c|c|c|c|c|c|}
\hline & Coefficient & Std Error & $t$-stat & Prob > |t $\mid$ & Adj-R2 & DW \\
\hline$\mu$ & 0.0000 & 0.0001 & -0.27 & 0.7873 & 0.7879 & 2.672 \\
\hline$\lambda$ & 0.5418 & 0.0108 & 50.19 & 0.0001 & & \\
\hline $\begin{array}{l}\text { Implied } \\
\text { rho }\end{array}$ & 0.9325 & & & & & \\
\hline
\end{tabular}

\section{GARCH $(1,1)$}

Daily returns (price appreciation) for S\&P500 index from CRSP

4551 observations (1975-1992)

Maximum Likelihood estimation with Normal as the underlying density

\begin{tabular}{|c|c|c|c|c|c|c|c|}
\hline & Coefficient & Std Error & t-stat & $\begin{array}{l}\text { Robust } \\
\text { Std Err }\end{array}$ & $\begin{array}{l}\text { Robust t- } \\
\text { stat }\end{array}$ & $\begin{array}{l}\text { Ljung- } \\
\text { Box(15) }\end{array}$ & \begin{tabular}{|l|} 
Jarque- \\
Bera(1980) \\
normality test \\
\end{tabular} \\
\hline$\omega$ & 0.0000 & 0.0000 & 7.95 & 0.0000 & 2.6404 & 10.26 & 5808.86 \\
\hline$\alpha$ & 0.0671 & 0.0018 & 37.14 & 0.0399 & 1.6829 & & \\
\hline$\beta$ & 0.9116 & 0.0049 & 187.96 & 0.0398 & 22.9188 & & \\
\hline
\end{tabular}

\section{GARCH Components Model}

Daily returns (price appreciation) for S\&P500 index from CRSP 4551 observations (1975-1992)

Maximum Likelihood estimation with Students-t as the underlying density

\begin{tabular}{|c|c|c|c|c|c|c|c|}
\hline & Coefficient & Std Error & $t-s t a t$ & $\begin{array}{l}\text { Robust } \\
\text { Std Ert } \\
\end{array}$ & $\begin{array}{l}\text { Robust t- } \\
\text { stat }\end{array}$ & $\begin{array}{l}\text { Ljung- } \\
\text { Box(15) }\end{array}$ & \begin{tabular}{|l|} 
Jarque- \\
Bera(1980) \\
normality test
\end{tabular} \\
\hline$\omega$ & 0.0000 & 0.0000 & 1.27 & 0.0000 & 0.7238 & 25.08 & 13549.96 \\
\hline$\alpha$ & 0.0139 & 0.0405 & 0.34 & 0.0480 & 0.2897 & & \\
\hline$\beta$ & 0.9560 & 0.0377 & 25.37 & 0.1310 & 7.2958 & & \\
\hline$\phi$ & 0.0245 & 0.0422 & 0.58 & 0.0885 & 0.2767 & & \\
\hline$p$ & 0.9890 & 0.0087 & 113.96 & 0.0122 & 80.9810 & & \\
\hline
\end{tabular}


Table 3 - Hedge Ratios

Number of short term options to hold per long term option

$S=200, K=200$, all volatility forecasts $=.01$ daily

risk-free rate $=.0002$ daily

\begin{tabular}{|c|c|c|c|}
\hline Model & $\begin{array}{l}\text { Medium } \\
\text { Mat=20 } \\
\text { Short=5 }\end{array}$ & $\begin{array}{l}\text { Medium } \\
\text { Mat }=30 / \\
\text { Short }=10\end{array}$ & $\begin{array}{l}\text { Medium } \\
\text { Mat }=40, \\
\text { Short }=20\end{array}$ \\
\hline B-S Gamma & -0.50 & -0.57 & -0.70 \\
\hline B-S Vega & -2.00 & -1.73 & -1.41 \\
\hline GARCH $(1,1)$ gamma & -0.79 & -0.89 & -0.94 \\
\hline GARCH components gamma & -0.66 & -0.77 & -0.88 \\
\hline ARV vega & -1.26 & -0.99 & -0.87 \\
\hline Simulated GARCH(1,1) & אצs/ & -0.83 & \\
\hline $\begin{array}{l}\text { Simulated GARCH } \\
\text { components }\end{array}$ & & -0.78 & \\
\hline $\begin{array}{l}\text { Simulated GARCH } \\
\text { components with leverage }\end{array}$ & & -0.77 & \\
\hline
\end{tabular}

\begin{tabular}{|r|}
\hline $\begin{array}{l}\text { Average } \\
\text { hedge ratio } \\
\text { over sample }\end{array}$ \\
\hline-0.61 \\
\hline-1.80 \\
\hline-0.90 \\
\hline-0.82 \\
\hline-1.00 \\
\hline
\end{tabular}

\begin{tabular}{|l|r|}
\hline $\begin{array}{l}\text { Empirical Best Hedge, Call } \\
\text { Option }\end{array}$ & -0.50 \\
\hline $\begin{array}{l}\text { Empirical Best Hedge, Put } \\
\text { Option }\end{array}$ & -0.35 \\
\hline $\begin{array}{l}\text { Empirical Best Hedge, } \\
\text { Straddle }\end{array}$ & -0.55 \\
\hline
\end{tabular}


Table 4 - Option Hedging Results

Buy $100 \$$ portfolio of medium term positions. Construct hedge portfolio.

Rebalance daily.

Data : CBOE S\&P500 Index Options (Oct. 1, 1985 - Feb. 28, 1992)

Ljung-Box and ARCH tests are on first six lags of portfolio return

Regression is portfolio price change on contemporaneous S\&P500 Index change and square

For this table, the simple delta hedge uses the $\mathrm{GARCH}(1,1)$ one-step ahead volatility forecast

Hedging Medium Term Calls

\begin{tabular}{|c|c|c|c|c|c|}
\hline Position & $\begin{array}{c}\text { Average } \\
\text { Daily } \\
\text { Portfolio } \\
\text { Price } \\
\text { Change }\end{array}$ & $\begin{array}{c}\text { Standard } \\
\text { Deviation of } \\
\text { Daily } \\
\text { Portfolio } \\
\text { Price } \\
\text { Changes }\end{array}$ & $\begin{array}{l}\text { Raw } \\
\text { Data } \\
\text { Ljung- } \\
\text { Box } \\
\text { prob. (< } \\
\text {.01) }\end{array}$ & $\begin{array}{c}\text { Raw } \\
\text { Data } \\
\text { Engle } \\
\text { ARCH } \\
\text { prob. (< } \\
\text {.01) }\end{array}$ & $\begin{array}{c}\text { Regres } \\
\text { sion } F \\
\text { prob. } \\
(<.01)\end{array}$ \\
\hline $\begin{array}{l}100 \$ \text { Medium } \\
\text { Term Calls }\end{array}$ & 0.69 & 18.23 & & & * \\
\hline $\begin{array}{l}\text { 100\$ Medium } \\
\text { Term Calls Delta } \\
\text { Hedged }\end{array}$ & -0.44 & 9.27 & * & & * \\
\hline $\begin{array}{l}100 \$ \text { S\&P500 } \\
\text { Index }\end{array}$ & 0.04 & 0.96 & & & * \\
\hline $\begin{array}{l}\text { Black-Scholes } \\
\text { Delta-Gamma } \\
\text { Hedge }\end{array}$ & -0.12 & 8.94 & * & * & \\
\hline $\begin{array}{l}\text { Black-Scholes } \\
\text { Delta-Vega } \\
\text { Hedge }\end{array}$ & 0.81 & 13.29 & * & * & * \\
\hline $\begin{array}{l}\text { GARCH }(1,1) \\
\text { Delta-Gamma } \\
\text { Hedge }\end{array}$ & 0.07 & 9.40 & * & $\star$ & * \\
\hline $\begin{array}{l}\text { GARCH } \\
\text { Components } \\
\text { Delta-Gamma } \\
\text { Hedge } \\
\end{array}$ & 0.01 & 9.24 & * & * & \\
\hline $\begin{array}{l}\text { Autoregressive } \\
\text { Volatility Delta- } \\
\text { Vega Hedge }\end{array}$ & 0.26 & 9.87 & * & * & * \\
\hline $\begin{array}{l}\text { Best Constant } \\
\text { ex-post hedge }\end{array}$ & 0.06 & 8.88 & * & * & \\
\hline
\end{tabular}




\begin{tabular}{|c|c|c|c|c|c|}
\hline Hedge & $\begin{array}{c}\text { Average } \\
\text { Daily } \\
\text { Portfolio } \\
\text { Price } \\
\text { Change }\end{array}$ & \begin{tabular}{|c|} 
Standard \\
Deviation of \\
Unexpected \\
Daily \\
Portfolio \\
Price \\
Changes
\end{tabular} & $\begin{array}{l}\text { Raw } \\
\text { Data } \\
\text { Ljung- } \\
\text { Box } \\
\text { prob. (< } \\
.01)\end{array}$ & $\begin{array}{c}\text { Raw } \\
\text { Data } \\
\text { Engle } \\
\text { ARCH } \\
\text { prob. (< } \\
.01)\end{array}$ & $\begin{array}{l}\text { Regres } \\
\text { sion F } \\
\text { prob. } \\
(<.01)\end{array}$ \\
\hline $\begin{array}{l}100 \$ \text { Medium } \\
\text { Term Puts }\end{array}$ & -1.40 & 20.66 & & & * \\
\hline $\begin{array}{l}\text { 100\$ Medium } \\
\text { Term Puts Delta } \\
\text { Hedged }\end{array}$ & -0.34 & 9.59 & & & * \\
\hline $\begin{array}{l}100 \$ \text { S\&P500 } \\
\text { Index }\end{array}$ & 0.04 & 0.96 & & & * \\
\hline $\begin{array}{l}\text { Black-Scholes } \\
\text { Delta-Gamma } \\
\text { Hedge }\end{array}$ & -0.08 & 8.54 & * & * & \\
\hline $\begin{array}{l}\text { Black-Scholes } \\
\text { Delta-Vega } \\
\text { Hedge } \\
\end{array}$ & 0.60 & 16.73 & & " & * \\
\hline $\begin{array}{l}\text { GARCH(1,1) } \\
\text { Delta-Gamma } \\
\text { Hedge } \\
\end{array}$ & 0.09 & 9.35 & * & * & * \\
\hline $\begin{array}{l}\text { GARCH } \\
\text { Components } \\
\text { Delta-Gamma } \\
\text { Hedge } \\
\end{array}$ & 0.05 & 9.06 & * & * & \\
\hline $\begin{array}{l}\text { Autoregressive } \\
\text { Volatility Delta- } \\
\text { Vega Hedge }\end{array}$ & 0.26 & 10.87 & * & * & * \\
\hline $\begin{array}{l}\text { Best Constant } \\
\text { ex-post hedge }\end{array}$ & -0.38 & 8.88 & - & & \\
\hline
\end{tabular}


Hedging medium term straddles

\begin{tabular}{|c|c|c|c|c|c|}
\hline Hedge & $\begin{array}{c}\text { Average } \\
\text { Daily } \\
\text { Portfolio } \\
\text { Price } \\
\text { Change } \\
\end{array}$ & $\begin{array}{c}\text { Standard } \\
\text { Deviation of } \\
\text { Unexpected } \\
\text { Daily } \\
\text { Portfolio } \\
\text { Price } \\
\text { Changes } \\
\end{array}$ & $\begin{array}{c}\text { Raw } \\
\text { Data } \\
\text { Ljung- } \\
\text { Box } \\
\text { prob. (< } \\
\text {.01) }\end{array}$ & $\begin{array}{c}\text { Raw } \\
\text { Data } \\
\text { Engle } \\
\text { ARCH } \\
\text { prob. (< } \\
.01)\end{array}$ & $\begin{array}{l}\text { Regres } \\
\text { sion F } \\
\text { prob. } \\
(<\quad .01)\end{array}$ \\
\hline $\begin{array}{l}100 \$ \text { Medium } \\
\text { Term Straddles }\end{array}$ & -0.69 & 6.86 & & & 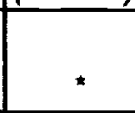 \\
\hline $\begin{array}{l}100 \$ \text { Medium } \\
\text { Term Straddles } \\
\text { Delta Hedged } \\
\end{array}$ & -0.60 & 6.85 & & & * \\
\hline $\begin{array}{l}100 \$ \text { S\&P500 } \\
\text { Index }\end{array}$ & 0.04 & 0.96 & & & * \\
\hline $\begin{array}{l}\text { Black-Scholes } \\
\text { Delta-Gamma } \\
\text { Hedge } \\
\end{array}$ & -0.25 & 6.02 & * & & \\
\hline $\begin{array}{l}\text { Black-Scholes } \\
\text { Delta-Vega } \\
\text { Hedge } \\
\end{array}$ & 0.66 & 11.41 & & * & * \\
\hline $\begin{array}{l}\text { GARCH }(1,1) \\
\text { Delta-Gamma } \\
\text { Hedge }\end{array}$ & -0.05 & 6.49 & * & * & * \\
\hline $\begin{array}{l}\text { GARCH } \\
\text { Components } \\
\text { Delta-Gamma } \\
\text { Hedge }\end{array}$ & -0.11 & 6.30 & * & & \\
\hline $\begin{array}{l}\text { Autoregressive } \\
\text { Volatility Delta- } \\
\text { Vega Hedge }\end{array}$ & 0.19 & 7.51 & * & ^ & * \\
\hline $\begin{array}{l}\text { Best Constant } \\
\text { ex-post hedge }\end{array}$ & -0.27 & 6.01 & * & * & \\
\hline
\end{tabular}




\section{Table 5 - Option Pricing Tests}

Value portfolio of $1: 1$ time spreads (calls, puts), jelly roll, medium and short term straddie. Sell if market price is greater than model price, otherwise buy. Rebalance daily.

* Average not different from zero at .01 level.

\begin{tabular}{|c|c|c|c|c|c|c|c|c|}
\hline Model & Always Buy & - ARV model & $\operatorname{GARCH}(1,1)$ & ne-step & $\operatorname{GARCH}(1,1)$ & avg vol & GARCH Compo & nents \\
\hline Position & $\begin{array}{c}\text { Average } \\
\text { Daily } \\
\text { Portfolio } \\
\text { Price } \\
\text { Change } \\
\end{array}$ & \begin{tabular}{|c|} 
Standard \\
Deviation of \\
Daily \\
Portfolio \\
Price \\
Changes \\
\end{tabular} & $\begin{array}{c}\text { Average } \\
\text { Daily } \\
\text { Portfolio } \\
\text { Price } \\
\text { Change } \\
\end{array}$ & $\begin{array}{c}\text { Standard } \\
\text { Deviation } \\
\text { of Daily } \\
\text { Portfolio } \\
\text { Price } \\
\text { Changes } \\
\end{array}$ & $\begin{array}{c}\text { Average } \\
\text { Daily } \\
\text { Portfolio } \\
\text { Price } \\
\text { Change } \\
\end{array}$ & \begin{tabular}{|c} 
Standard \\
Deviation of \\
Daily \\
Portfolio \\
Price \\
Changes \\
\end{tabular} & $\begin{array}{c}\text { Average } \\
\text { Daily } \\
\text { Port folio } \\
\text { Price Change } \\
\end{array}$ & $\begin{array}{c}\text { Standard } \\
\text { Deviation of } \\
\text { Daily } \\
\text { Portfolio } \\
\text { Price } \\
\text { Changes } \\
\end{array}$ \\
\hline $\begin{array}{l}1 \text { position } \\
1: 1 \text { Call } \\
\text { Time Spread }\end{array}$ & $* 0.008$ & 0.99 & 0.17 & 0.97 & 0.16 & 0.97 & 0.14 & 0.98 \\
\hline $\begin{array}{l}1 \text { position } \\
1: 1 \text { Put } \\
\text { Time Spread }\end{array}$ & $* 0.006$ & 0.82 & 0.15 & 0.81 & 0.18 & 0.81 & 0.18 & 0.80 \\
\hline $\begin{array}{l}1 \text { position } \\
\text { Jelly Roll }\end{array}$ & $* 0.003$ & 1.39 & 0.44 & 1.32 & 0.46 & 1.31 & 0.46 & 1.31 \\
\hline \begin{tabular}{|l|}
$100 \$$ \\
Medium \\
Term \\
Straddle \\
\end{tabular} & -0.69 & 6.86 & 1.06 & 6.81 & 0.81 & 6.84 & 1.00 & 6.82 \\
\hline $\begin{array}{l}100 \$ \text { Short } \\
\text { Term } \\
\text { Straddle }\end{array}$ & -1.48 & 11.52 & 1.61 & 11.50 & 1.62 & 11.50 & 1.54 & 11.51 \\
\hline
\end{tabular}

Summary of Trading Signals

\begin{tabular}{|c|c|c|c|c|}
\hline & Number of & Buy signals & & \\
\hline Position & ARV model & $\begin{array}{l}\operatorname{GARCH}(1,1) \\
\text { one-step }\end{array}$ & $\begin{array}{l}\operatorname{GARCH}(1,1) \\
\text { avg vol }\end{array}$ & $\begin{array}{l}\text { GARCH } \\
\text { Components }\end{array}$ \\
\hline $\begin{array}{l}1 \text { position } \\
\text { 1:1 Call } \\
\text { Time Spread }\end{array}$ & 654 & 50 & 46 & 38 \\
\hline $\begin{array}{l}1 \text { position } \\
1: 1 \text { Put } \\
\text { Time Spread }\end{array}$ & 654 & 126 & 137 & 126 \\
\hline $\begin{array}{l}1 \text { position } \\
\text { Jelly Roll }\end{array}$ & 654 & 134 & 155 & 157 \\
\hline $\begin{array}{l}100 \$ \\
\text { Medium } \\
\text { Term } \\
\text { Straddle }\end{array}$ & 654 & 49 & 31 & 24 \\
\hline $\begin{array}{l}100 \$ \text { Short } \\
\text { Term } \\
\text { Straddle }\end{array}$ & 654 & 82 & 43 & 45 \\
\hline
\end{tabular}

Average Profit on Buy/Sell different from 0 at .01 level

+ indicates significantly positive profit, $0=$ insignificant, - = negative First entry is buy / Second entry is sell

\begin{tabular}{|l|c|c|c|c|}
\hline Position & ARV Model & $\begin{array}{l}\text { GARCH }(1,1) \\
\text { one-step }\end{array}$ & $\begin{array}{l}\text { GARCH( } 1,1) \\
\text { avg vol }\end{array}$ & $\begin{array}{l}\text { GARCH } \\
\text { Components }\end{array}$ \\
\hline $\begin{array}{l}1 \text { position } \\
1: 1 \text { Call Time } \\
\text { Spread }\end{array}$ & $0 / 0$ & $+/+$ & $+/+$ & $+/+$ \\
\hline $\begin{array}{l}1 \text { position } \\
1: 1 \text { Put Time } \\
\text { Spread }\end{array}$ & $0 / 0$ & $+/+$ & $+/+$ & $+/+$ \\
\hline $\begin{array}{l}1 \text { position } \\
\text { Jelly Roll }\end{array}$ & $0 / 0$ & $+/+$ & $+/+$ & $+/+$ \\
\hline $\begin{array}{l}100 \$ \\
\text { Medium } \\
\text { Term } \\
\text { Straddle }\end{array}$ & $-/ 0$ & $0 /+$ & $0 /+$ & $0 /+$ \\
\hline $\begin{array}{l}100 \$ \text { Short } \\
\text { Term } \\
\text { Straddle }\end{array}$ & $-/ 0$ & $0 /+$ & $0 /+$ & $0 /+$ \\
\hline
\end{tabular}


Figure 1 - Term Structure of Black-Scholes Vega

$(S=100, K=100, \mathrm{sig}=.01, \mathrm{rf}=.0002)$

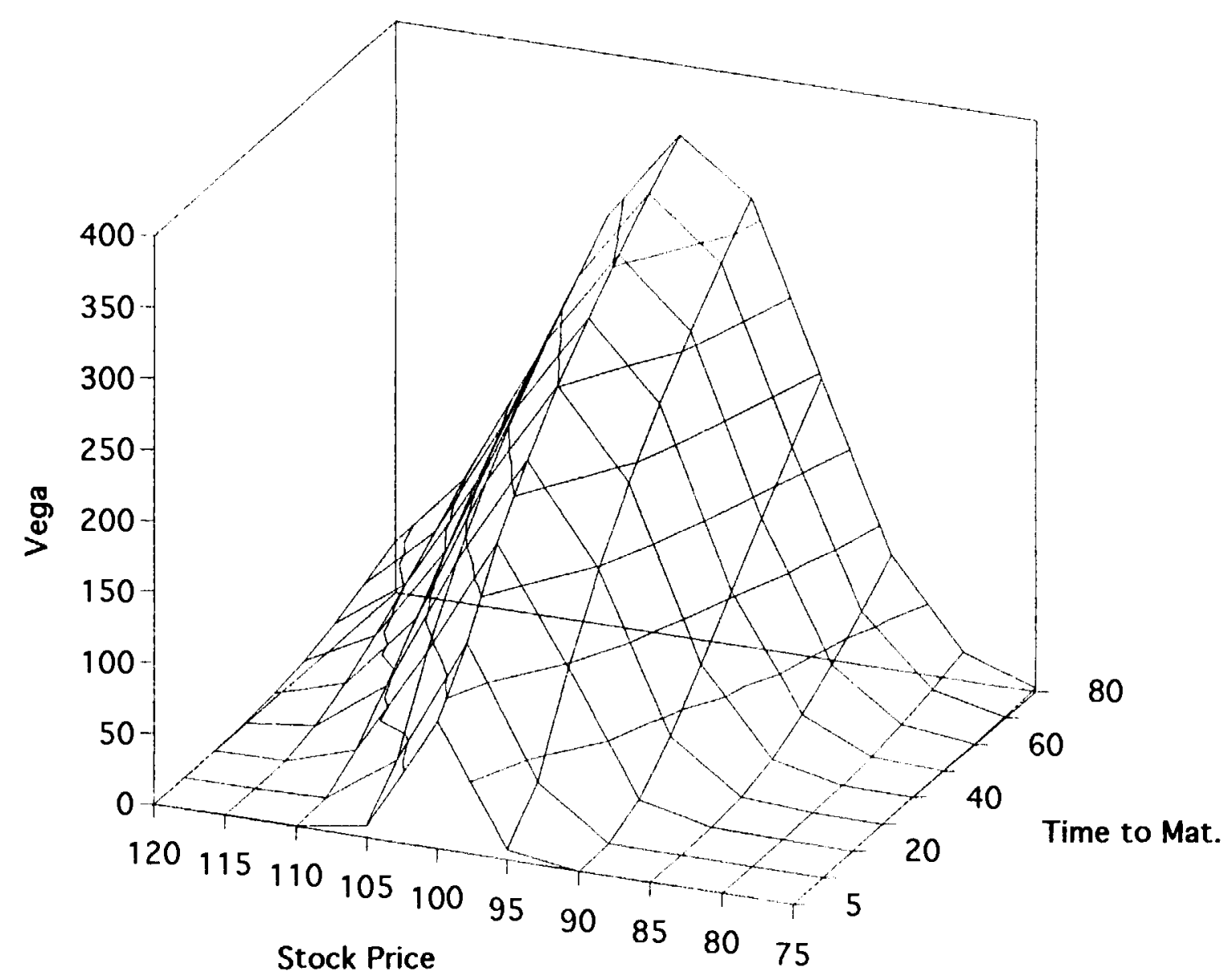


Figure 2 - Term Structure of Black-Scholes Gamma

$(S=100, K=100, \mathrm{sig}=.01, \mathrm{rf}=.0002)$

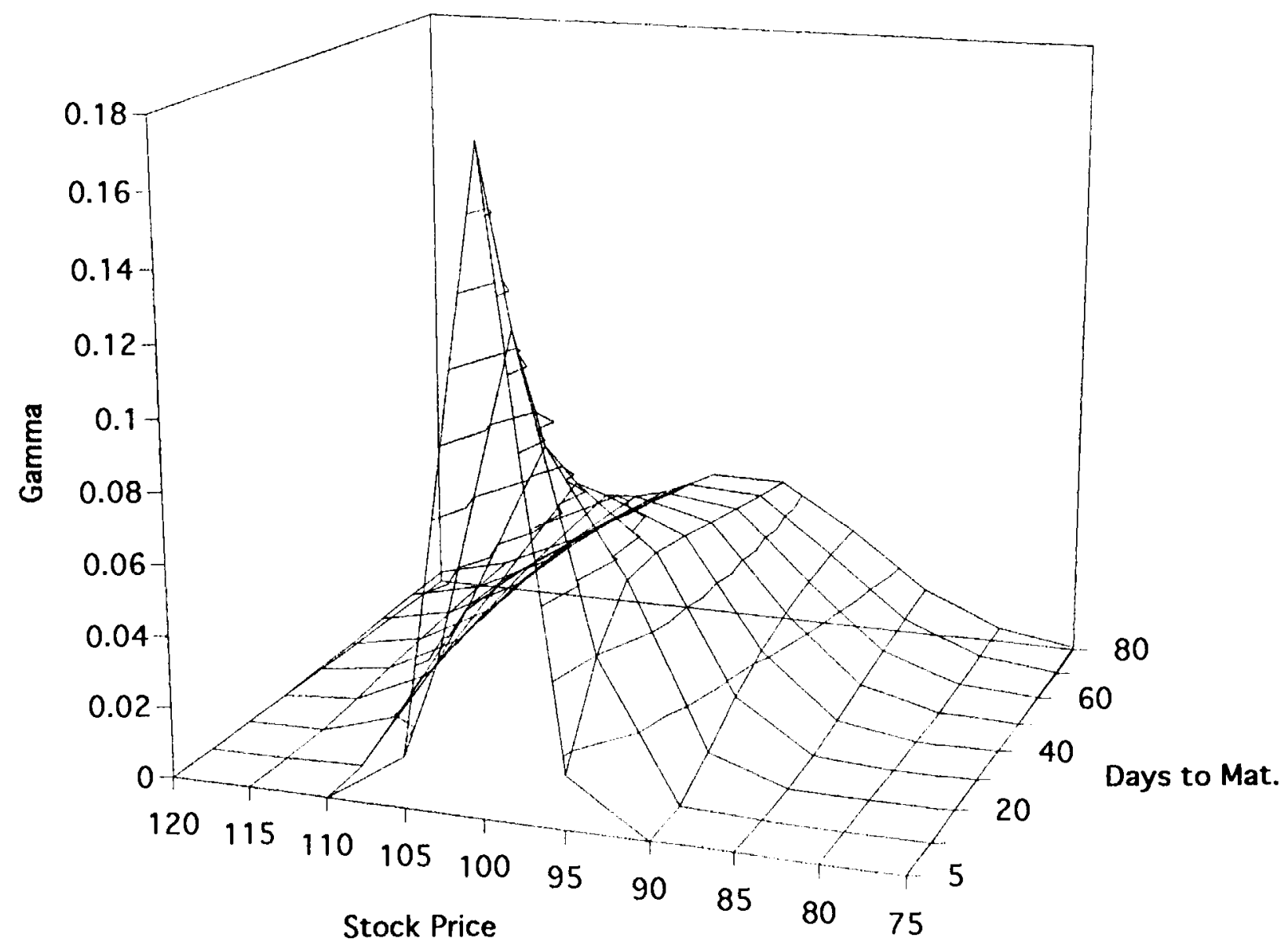

